\title{
Spatial Analysis of Industrial Green Development and Sustainable Cities in the Yellow River Basin
}

\author{
Ke Liu, ${ }^{1}$ Huan Jiang, ${ }^{1}$ and Qian Zhou $\mathbb{D}^{2}$ \\ ${ }^{1}$ School of Economics and Management, Zhengzhou University of Light Industry, Science Avenue 136, ZhengZhou, \\ Henan 450000, China \\ ${ }^{2}$ Economics School, Zhongnan University of Economics and Law, Nanhu Avenue 182, Wuhan, Hubei 430073, China \\ Correspondence should be addressed to Qian Zhou; zhouqian200912@163.com
}

Received 11 February 2021; Revised 25 March 2021; Accepted 23 April 2021; Published 4 May 2021

Academic Editor: Victor Shi

Copyright (c) $2021 \mathrm{Ke} \mathrm{Liu} \mathrm{et} \mathrm{al.} \mathrm{This} \mathrm{is} \mathrm{an} \mathrm{open} \mathrm{access} \mathrm{article} \mathrm{distributed} \mathrm{under} \mathrm{the} \mathrm{Creative} \mathrm{Commons} \mathrm{Attribution} \mathrm{License,} \mathrm{which}$ permits unrestricted use, distribution, and reproduction in any medium, provided the original work is properly cited.

\begin{abstract}
The Yellow River Basin (YRB) is an important ecological defense and economic zone in China and occupies a very important position in the economy and society of China. Premise condition of ecological protection and development of high quality in YRB is the greening of the industry. Based on the data of 35 cities in YRB in 2012, 2015, and 2018, this paper constructs an evaluation index system for the industrial green development (IGD) and explores spatial differentiation characteristics of the IGD by the exploratory spatial data analysis (ESDA) method. On this basis, this paper uses the geographical weighted regression (GWR) model to analyze the influencing factors. The results indicate the following: (1) in general, IGD in YRB shows an upward trend. (2) The Global Moran's I index of IGD shows a small increase; the distribution of local spatial correlation is basically unchanged. (3) There are obvious regional differences in the influencing factors of IGD. The degree of influence of each factor on IGD is openness $>$ industrial upgrading index $>$ urbanization rate $>$ science and technology expenditures $>$ reduction rate of energy consumption.
\end{abstract}

\section{Introduction}

China's economy has been improving rapidly and plays an important role in the world in recent years. However, insufficient awareness of ecological protection in the course of economic development has led to the emergence of many environmental problems, seriously affecting people's lives, health, and happiness, which has attracted great attention of the state. In China, the concept of "green development" was first put forward at a meeting of the Political Bureau of the CPC Central Committee in 2015. In the 18th CPC National Congress, "lucid waters and lush mountains are invaluable assets" was proposed. The 19th CPC National Congress set the building of a beautiful China as the goal of socialist modernization. This process reflects the state's policy of gradually attaching great importance to ecological and environmental protection.
Ecological protection and high-quality development of YRB have become a national strategy in 2019. The development of YRB has been ushered in unprecedented opportunities, and great efforts must be made to greatly harness and protect YRB. In order to promote the highquality development and ecological protection [1] of YRB, it is essential to build a modern industrial development system and realize IGD. Therefore, scientific evaluation and accurately grasping the influencing factors that cause the difference of IGD in various regions can provide the decisionmaking basis for the industrial pattern of YRB and promote the high-quality development of YRB.

Based on this, in this paper, we use YRB as the research sample and construct IGD evaluation system. The entropy method is used to assess it, while exploratory spatial data analysis (ESDA) is used to analyze spatial characteristics. Further, this paper uses GWR model to analyze the 
influencing factors of IGD in YRB, with expectation of providing a reference basis.

\section{Literature Review}

In the new era, green development is a kind of sustainable development pattern of harmonious coexistence between human and nature. Green development originates from "ecological economy" and "green economy," with the increasingly prominent role of ecological environment, and green economy, as a new development model, has been widely concerned by international organizations (institutions) and scholars. In addition, industrial development is the main source of material wealth and one of the main reasons for the destruction of the ecological environment [2]. Therefore, it is particularly important to explore IGD.

2.1. Connotation of IGD. IGD originated from "green economy" [3]. Its purpose was to construct a sustainable development mode with harmonious economy, ecology, and society. Green development refers to the ecological environment under the control of capacity and resources bearing capacity, by protecting the natural environment to realize the sustainable development of the new development pattern and the concept of ecological development [4]. Its core is to establish and form a coordinated interaction mechanism of economy, nature, and society [5]. Sustainable development models, such as "green economy," "low-carbon economy," "ecological economy," and "circular economy," all embody the concept of green development from different perspectives [6]. Although being with the same connotation of sustainable development, green development emphasizes the symbiosis of "green" and "development" without compromising the ability to regenerate resources and environment, and without reducing the level of economic and social welfare [7], it is more prominent in the "development" on the basis of sustainability. IGD requires sustainable development and ecological civilization construction from the industrial level, aiming at building an industrial structure and production model with high science and technology content, low resource consumption, and less environmental pollution, so as to realize the organic coordination between economic development and resource environment.

2.2. Evaluation of IGD. IGD is requirement of green development from the industrial level. Measuring green development falls into two categories: efficiency of green development and comprehensive index system [8]. The first is to assess green development by introducing the efficiency [8-12]. Another approach is to establish an index system to comprehensively measure IGD. According to the different regions and emphases of the research, the comprehensive index system is mainly established from the following aspects: the first green development indicators were set up by the OECD [13]. Based on this index system, many scholars have carried out a series of researches. Existing researches mainly construct IGD index system from three dimensions of industry, resource environment, and government policy
[14-16]. There are also some studies evaluating the index from different industrial structures $[17,18]$.

2.3. Influencing Factors of IGD. There is still no complete conclusion on the factors affecting IGD, which mainly include the following aspects: environmental policy, government investment $[19,20]$, advances in technology, industrial structure [21], economic opening [22, 23], and urban size $[24,25]$. Some studies showed that government regulation [16] and environmental regulation [19] had a significant positive effect on IGD, promoting industrial transformation and upgrading through government regulation [18], to promote the process of IGD. Besides, the government increasing investment in science, technology, energy conservation, and environmental protection through financial means was also beneficial to IGD [26]. At the same time, we cannot ignore the negative impact of the rapid urban expansion [27], low energy utilization [23], and blind utilization of foreign capital [22] on IGD.

2.4. Summary. Through combing the existing literatures, it is found that the evaluation and influencing factors of IGD are relatively mature, which provides a relatively perfect research basis for this paper. However, the existing researches are deficient in spatiotemporal differentiation. Compared with the existing researches, the innovations of this paper are as follows. (1) Research sample: ecological protection and high-quality development of YRB have become a national strategy, and the study of this region has great practical significance. (2) Research conclusions: by comparing the regression coefficient, it is found that the influence of openness is greater than that of industrial advanced index on the IGD in YRB, which is different from the previous conclusion [28]. The sample of this paper is YRB, which is relatively targeted, so it has certain reference value for the policy formulation of high-quality development of YRB.

\section{Research Area and Research Methods}

3.1. Overview of Research Area. On the basis of YRB trunk stream area demarcated by the Yellow River Commission of the Ministry of Water Resources, comprehensively considering the natural conditions, administrative divisions, and economic development of each city, as well as the representativeness and availability of data, this paper determines 35 cities in 7 provinces of Shanxi, Inner Mongolia, Shandong, Henan, Shaanxi, Gansu, and Ningxia (Figure 1).

\subsection{Research Method}

3.2.1. Entropy Method. The entropy method is an impersonal assignment. It determines the weight of each index according to its own statistical attribute, avoiding subjective incompleteness [29-31]. Therefore, entropy method is adopted in this paper to measure IGD of 35 cities along YRB. According to Chen et al. [32], the specific calculation steps are as follows: 
(1) Data standardization: because the dimensions and orders of magnitude of the original data for each indicator are different, standardized processing is required to eliminate the impact on the evaluation.

Positive indicators:

$$
Y_{i j}=\frac{X_{i j}-\min \left(X_{i j}\right)}{\max \left(X_{i j}\right)-\min \left(X_{i j}\right)} .
$$

Negative indicators:

$$
Y_{i j}=\frac{\max \left(X_{i j}\right)-X_{i j}}{\max \left(X_{i j}\right)-\min \left(X_{i j}\right)} .
$$

Among them, $Y_{i j}$ is the standardized matrix, and $X_{i j}$ is the original data matrix.

(2) Calculate the entropy value of index:

$$
e_{j}=-k \sum_{i=1}^{n} P_{i j} \ln \left(P_{i j}\right) \text {. }
$$

Among them, $k=1 / \ln (n), P_{i j}=Y_{i j} / \sum_{i=1}^{n} Y_{i j} ; e_{j}$ is the entropy value, $n=35$.

(3) Calculate index weight:

$$
W_{i j}=\frac{\left(1-e_{i j}\right)}{\sum_{i=1}^{m}\left(1-e_{i j}\right)} .
$$

Among them, $W_{i j}$ is the index weight, $m=18$.

(4) Calculate the comprehensive score:

$$
S_{i}=\sum_{i=1}^{m} W_{i j} P_{i j} \text {. }
$$

Among them, $S_{i}$ is the level of IGD.

3.2.2. Exploratory Spatial Data Analysis. ESDA is a datadriven method to study spatial distribution characteristics, which mainly includes global spatial autocorrelation and local spatial autocorrelation. We use ESDA to study spatial distribution characteristics of IGD in YRB.

(1) Global Spatial Autocorrelation. Global spatial autocorrelation can measure the clustering degree of the study area. In this paper, Global Moran's I is selected to evaluate spatial characteristics of the IGD level in YRB and find out their correlation and differences. According to Ren et al. [33], the calculation formula is

$$
\text { Moran s } I=\frac{\sum_{i=1}^{n} \sum_{j=1}^{n} W_{i j}\left(X_{i}-\bar{X}\right)\left(X_{j}-\bar{X}\right)}{S^{2} \sum_{i=1}^{n} \sum_{j=1}^{n} W_{i j}} .
$$

Among them, $\bar{X}=(1 / n) \sum_{i=1}^{n} X_{i} ; S^{2}=(1 / n) \sum_{i=1}^{n}\left(X_{i}{ }^{-}\right.$ $\bar{X})^{2} ; n$ is the sample size; $X_{i}$ and $X_{j}$ are the IGD levels of regions $i$ and $j ; W_{i j}$ is the spatial weight matrix. Usually, the range of Moran's $I$ is $(-1,1)$. If Moran's $I>0$, the areas with similar IGD are clustered, while Moran's $I<0$ means that IGD is scattered.

(2) Locally Spatial Autocorrelation. This paper adopts the cold and hot spot analysis method and uses Getis-Ord G* index to evaluate the local regional spatial characteristics of industrial development in YRB. The calculation formula is in accordance with $\mathrm{Hu}$ et al. [34]:

$$
G_{i}^{*}(d)=\frac{\sum_{i=1}^{n} W_{i j}(d) X_{i}}{\sum_{i=1}^{n} X_{i}} .
$$

Among them, $X_{i}$ is the IGD of region $i$. If $G_{i}^{*}(d)>0$, IGD around city $i$ is relatively high, and it is a hot spot; while if $G_{i}^{*}(d)<0$, IGD around city $i$ is relatively low, and it is a cold spot area.

3.2.3. Geographical Weighted Regression Model. GWR model was proposed by Fotheringham [35]. Based on local regression analysis, the spatial position of data is embedded into regression parameters to measure the spatial instability of various geographical variables, which is conducive to the exploration of spatial law. Therefore, the GWR model is adopted in this paper to analyze the spatial heterogeneity of the driving forces of IGD in YRB. According to Chen et al. [36], the calculation formula is

$$
y_{i}=\beta_{0}\left(u_{i}, v_{i}\right)+\sum_{j=1}^{n} \beta_{j}\left(u_{i}, v_{i}\right) x_{i j}+\varepsilon_{i} .
$$

Among them, $y_{i}$ is the global dependent variable, $x_{i j}$ is the influencing factor, $\beta_{0}\left(u_{i}, v_{i}\right)$ is a constant term, $\left(u_{i}, v_{i}\right)$ are the spatial coordinates of the $i$-th region, $\beta_{j}\left(u_{i}, v_{i}\right)$ is the parameter of region $x_{i j}$, and $\varepsilon_{i}$ is the random error term.

3.3. Index System Establishment and Data Source. The connotation of IGD requires that economic development of high quality should be compatible with ecological protection. It emphasizes that economic development also takes into account ecological protection. From the perspective of IGD, it is required that urban economic development should focus on quality improvement on premise of sustainable development. The IGD in YRB needs green transformation through three industries together to achieve green and highquality economic growth [37]. Industrial development changes with the utilization of resources and ecological environment. The essence of green development is sustainable development, by raising the utilization rate of resources, improving the environmental conditions to relieve the contradiction between economic development and ecological protection [38]. However, only depending on market regulation is not enough while pursuing the dynamic balance of economic development and ecological protection, and support of the government is quite essential [16]. Therefore, based on the previous, we construct an evaluation index system of IGD in 35 cities in YRB from three dimensions of green economic growth, resource, and 
environment carrying capacity and government support (Table 1).

In terms of green economic growth, it mainly measures economic level of the region and the green level of the three industries [39]. The economic density and per capita GDP are used to reflect the economic development status of the region to measure the green growth potential. The green development level of primary industry is measured by grain yield and fertilizer use. The secondary industry is the main reason for green development, which is measured by GDP of industries above designated scale, number of enterprises above designated scale, and comprehensive utilization rate of solid waste. The proportion of the added value of the tertiary industry in GDP and the number of employees in the tertiary industry will be used to assess IGD of the tertiary industry.

In terms of resource and environment carrying capacity, the index system is mainly used to measure the abundance of regional resources and the environmental governance status of enterprises [40]. Cities around YRB are rich in resources. Considering the availability of data, the abundance of resources is measured by the total amount of water resources. The emission of waste water, the emission of sulfur dioxide, and the emission of soot are used to measure the environmental governance status of enterprises.

In terms of government support, the role of government in IGD is extremely important [41]. The established indicator system measures the government's investment in environmental protection from three aspects: (1) expenditure on energy conservation and environmental protection; (2) green coverage rate and per capita park area in built-up areas; (3) harmless treatment rate of domestic waste and sewage treatment rate.

Considering the timeliness and availability of data, and there must be at least three years to study the change of IGD, the data in this paper are 2012, 2015, and 2018. The sources are mainly China City Statistical Yearbook in 2013, 2016, and 2019, Statistical Yearbooks for all provinces of YRB, Statistical Yearbooks for all cities, and Bulletin of National Economic and Social Development. Some of the missing data were supplemented by interpolation method.

\section{Spatial Differentiation of IGD in YRB}

4.1. Comprehensive Analysis of IGD. The scores of IGD level of 35 cities in YRB in 2012, 2015, and 2018 are calculated by entropy method. We find that the change of IGD in YRB has certain rules (Figure 2). (1) From the perspective of spatial weight, that of green economic growth (0.6652) in the criterion layer is the largest, followed by government support (0.2281), and the smallest is resource and environment carrying capacity (0.1067). This shows that the indicators of green economic growth have a greater impact on IGD in YRB, while those of government support and resource and environment carrying capacity are decreasing in order. (2) From the perspective of spatial distribution, IGD in YRB shows trend of "high in the east and low in the west." The scores of Zhengzhou, Dezhou, Zibo, and Heze are relatively high, while those of Baiyin, Zhongwei, Wuzhong, and
Shizuishan are low. This is because Zhengzhou is the national central city in YRB, taking the lead in transformation and upgrading of industries, and is the main position of high-tech industry transfer. In addition, the tertiary industry accounts for a relatively high proportion. In urban areas, most of them are high-value-added industries. Pollution and low-value-added enterprises have been eliminated, transferred, and upgraded, which have little negative impact on the ecological environment. Therefore, Zhengzhou's IGD level is higher. Baiyin and Zhongwei are located in the western region. Due to backward economic development and small proportion of the tertiary industry, they are difficult to develop high-value-added industries by relying on their own strength. They have become the traditional manufacturing industry's undertaking site and are highly dependent on energy and resources, so their green development level is relatively low. (3) From the perspective of spatial evolution characteristics, the spatial pattern of IGD in YRB in 2012, 2015, and 2018 is relatively stable, while the polarization difference is relatively obvious. The average score of IGD in each city rose from 0.2968 in 2015 to 0.3132 in 2018, and the range rose from 0.4371 in 2012 to 0.5448 in 2018, indicating that IGD in each region of YRB has been improved, but the gap between cities is getting larger and larger. This is because the Central Plains city group was approved as a national city group relatively early and has a large leading advantage, while the Lanxi city group was approved as a national city group in 2018 and started late, leading to a relatively significant phenomenon of spatial polarization.

\subsection{Spatial Characteristics of IGD}

4.2.1. Overall Spatial Characteristics of IGD. For quantitatively studying the spatial pattern evolution of IGD in YRB, Queen's adjacency matrix is adopted as the spatial weight, and ArcGIS10.2 is used to calculate the Global Moran's I at the comprehensive level of IGD in YRB in 2012, 2015, and 2018. The results show that the Global Moran's $I$ in the three years are all positive and passed the test at the significance level of 0.01 (Table 2). This indicates that IGD in YRB presents a significant positive spatial autocorrelation in 2012, 2015, and 2018. The rising trend of Global Moran's I reflects the increasing spatial concentration. This is because the development of urban agglomerations and metropolitan areas has achieved remarkable results, and national policies are increasingly inclined to overall planning, which has strengthened the links between cities.

4.2.2. Local Spatial Correlation Characteristics of IGD. In order to make up for the influence of global autocorrelation that cannot reflect local correlation characteristics and further reveal the spatial correlation pattern of IGD in YRB, the cold and hot spot analysis method is adopted, and ArcGIS10.2 is used to draw the spatial cold and hot spot distribution map of IGD in YRB in 2012, 2015, and 2018 (Figure 3). Figure 3 shows that, overall, there is no substantial change in the pattern of cold and hot spots for the 


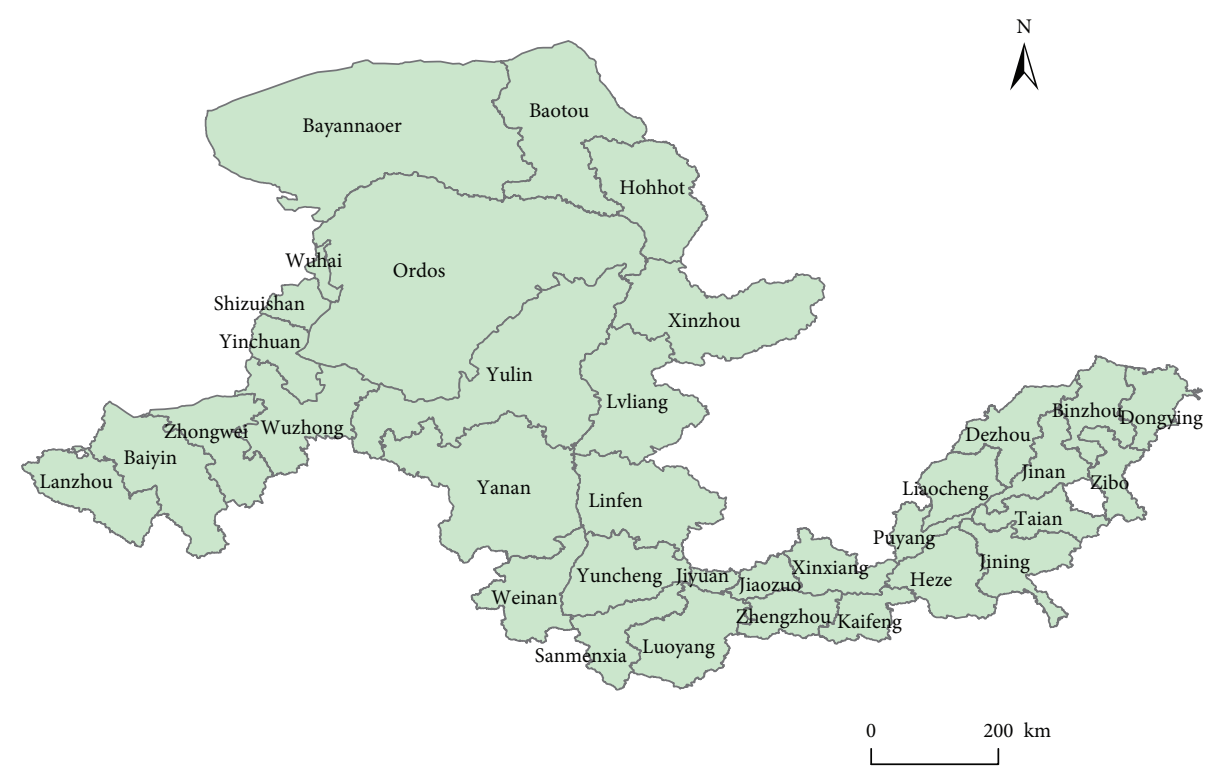

FIgURE 1: Topographic map of YRB and sample of this paper.

TABLE 1: IGD evaluation index system of cities in YRB.

\begin{tabular}{|c|c|c|c|}
\hline Target layer & Criterion layer & Variable & Index \\
\hline \multirow{12}{*}{$\begin{array}{l}\text { Industrial } \\
\text { green } \\
\text { development } \\
\text { level }\end{array}$} & \multirow{6}{*}{ Green economic growth } & Green growth potential & $\begin{array}{c}\text { Economic density } \\
\text { Per capita GDP } \\
\text { Grain yield } \\
\text { Fertilizer use }\end{array}$ \\
\hline & & & $\begin{array}{l}\text { The gross output value of industries above designated } \\
\text { scale }\end{array}$ \\
\hline & & Secondary industry & $\begin{array}{l}\text { Number of enterprises above designated scale } \\
\text { Comprehensive utilization rate of solid waste }\end{array}$ \\
\hline & & Tertiary it & Proportion of added value in GDP \\
\hline & & lertiary 1 & Number of employees in the tertiary industry \\
\hline & & Abundance of resources & Total amount of water resources \\
\hline & \multirow{3}{*}{$\begin{array}{c}\text { Resource and environment carrying } \\
\text { capacity }\end{array}$} & Environmental & Emission of waste water per unit of GDP \\
\hline & & $\begin{array}{l}\text { Environmental } \\
\text { conditions }\end{array}$ & $\begin{array}{l}\text { Emission of sulfur dioxide per unit of GDP } \\
\text { Emission of soot per unit of GDP }\end{array}$ \\
\hline & & Government investment & $\begin{array}{l}\text { Expenditure on energy conservation and environmental } \\
\text { protection }\end{array}$ \\
\hline & \multirow{3}{*}{$\begin{array}{l}\text { Government } \\
\text { support }\end{array}$} & $\mathrm{Ir}$ & Green coverage rate \\
\hline & & & Per capita park area in built-up areas \\
\hline & & $\begin{array}{l}\text { Environmental } \\
\text { governance }\end{array}$ & $\begin{array}{c}\text { Harmless treatment rate of domestic waste } \\
\text { Sewage treatment rate }\end{array}$ \\
\hline
\end{tabular}

IGD in YRB, which maintains the characteristic of "high in the east and low in the west." From the point of economic development, Shandong and Henan are better than Inner Mongolia, Shanxi, and Gansu. It can be said that economic development can drive the local of IGD. In the three years, the hot spots are concentrated in the east (Jinan, Binzhou, Zibo, Tai'an, Liaocheng, and Dezhou), while the cold spots are mainly in the west (Baiyin, Zhongwei, and Wuzhong), with clear polarization between the east and the west. From the perspective of the number of cold and hot spots, the hot is increasing, from 9 in 2012 to 11 in 2018. The increasing cities are Zhengzhou, Xinxiang, Liaocheng, and Jining. The number and spatial distribution of cold spots remained basically unchanged, increasing from 9 in 2012 to 11 in 2018. This is because there are many hot spots in Shandong province, among which Jinan and Dezhou have played a 
2012

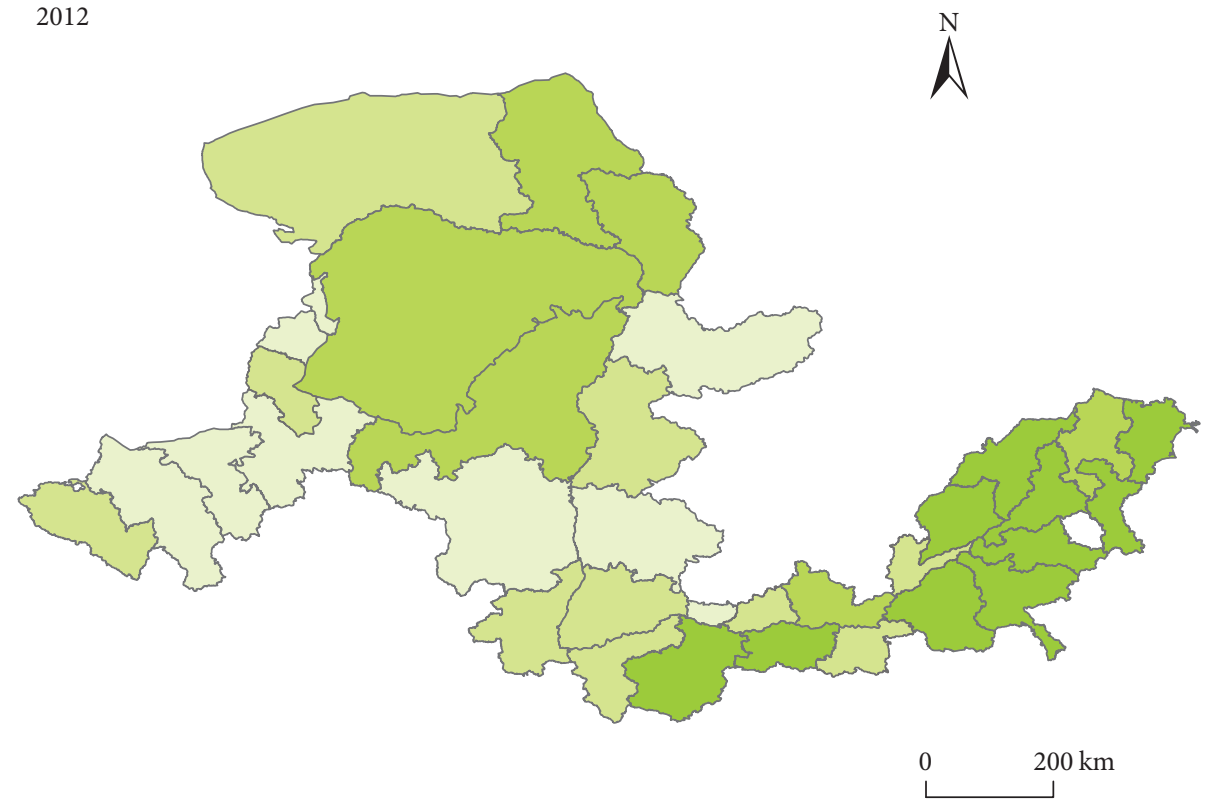

$\begin{array}{ll}0.1454-0.2161 & \square \\ 0.2161-0.2930 & \\ \square & 0.2930-0.4159-0.5825\end{array}$

(a)

2015

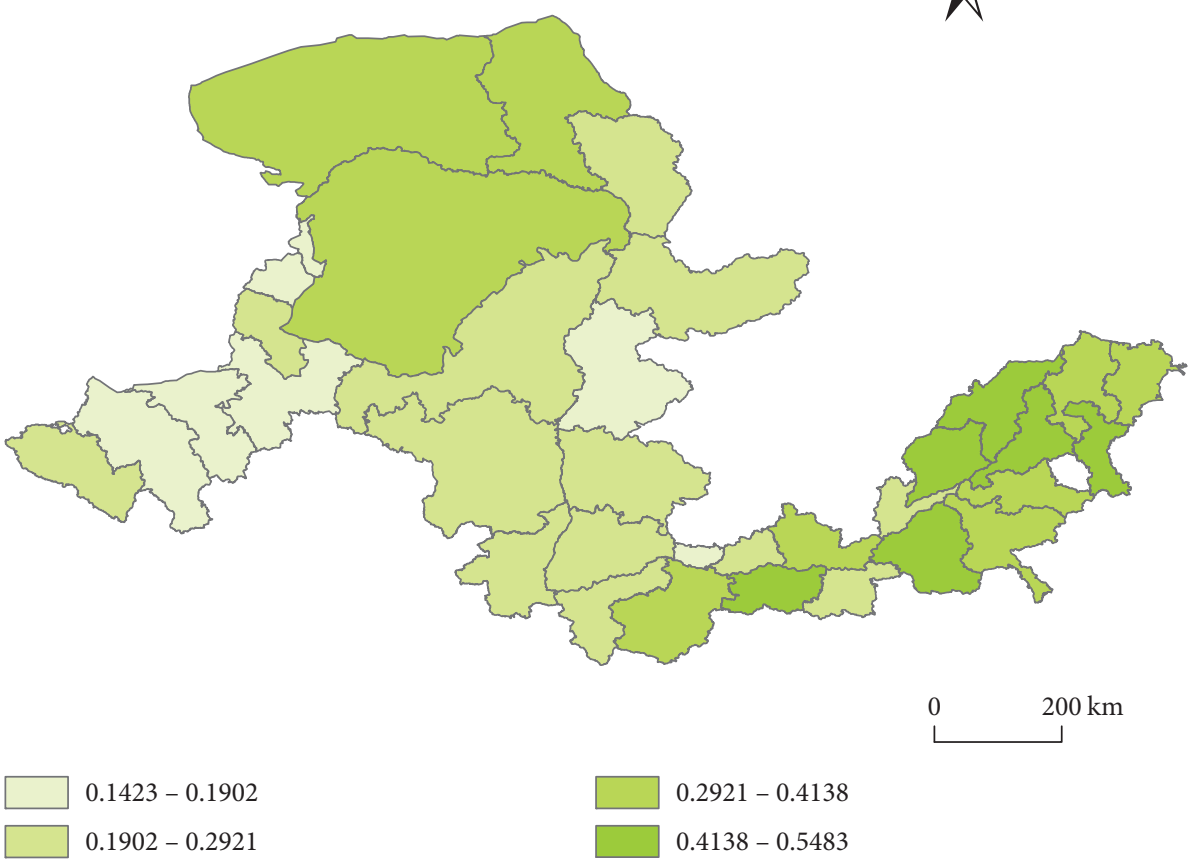

(b)

Figure 2: Continued. 


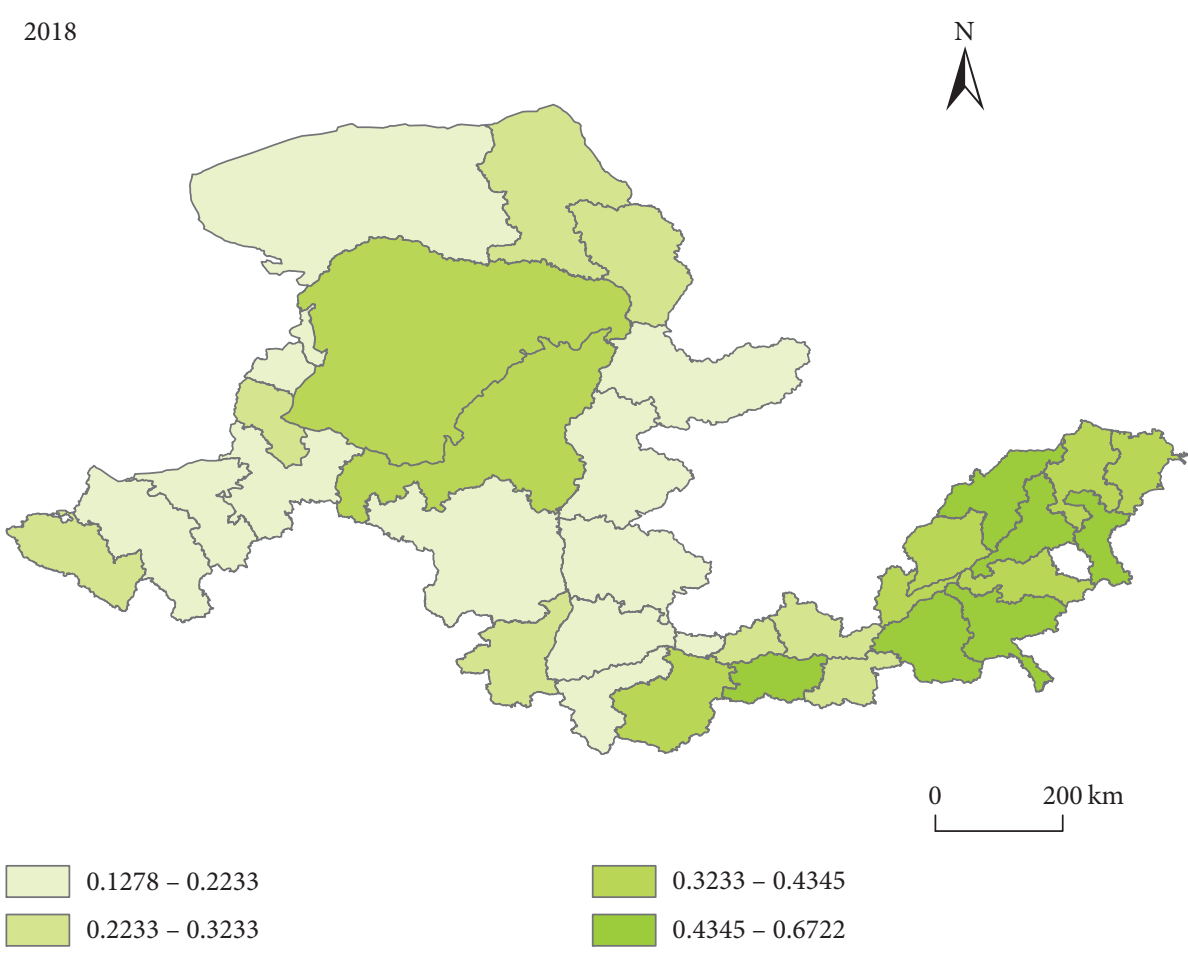

(c)

FIGURE 2: IGD of cities in YRB in 2012, 2015, and 2018.

TABLE 2: Moran's I of IGD in YRB in 2012, 2015, and 2018.

\begin{tabular}{ccccc}
\hline Year & Moran's $I$ & $E(I)$ & $Z(I)$ & $P(I)$ \\
\hline 2012 & 0.3258 & -0.2941 & 3.0308 & 0.0024 \\
2015 & 0.3522 & -0.2941 & 3.2763 & 0.0010 \\
2018 & 0.3680 & -0.2941 & 3.4517 & 0.0006 \\
\hline
\end{tabular}

leading role in the surrounding cities. Zhengzhou's relatively rapid development has driven the development of Kaifeng, Xinxiang, and other cities, while the western region lacks hot cities to drive the green development of regional industries. In addition, from 2012 to 2018, the number of hot spot areas and secondary hot spot areas decreased, and the number of cold spot areas and secondary cold spot areas increased, indicating that the gap in industrial green development level of IGD within the YRB is narrowing.

\section{Analysis of Influencing Factors on IGD in YRB}

5.1. Influencing Factor Analysis Framework. The level of IGD is affected by many factors, and the formation mechanism is relatively complex. Combing existing literatures, scholars generally believe that industrial structure [21, 26], urban development potential [8, 42], energy efficiency [23, 42], degree of openness [16, 22], and government support $[20,42]$ have significant effects on IGD. Therefore, this paper selects these five aspects as the influencing factors (Table 3 ). In order to prevent the collinearity of the indicators from causing deviations in the research results, SPSS is used to conduct collinearity test for these five indicators (Table 4). The results showed that the variance inflation factor (VIF) was less than 10, and the conditional index (CI) was less than 30 , indicating that there is no collinearity.

5.2. Spatial Heterogeneity of Influencing Factors. In this paper, ArcGIS10.2 is used to conduct OLS regression analysis for these 5 indicators, and the results are shown in Table 5. In Table 5, $R^{2}=0.24, \mathrm{AICc}=-35.52$, indicating that this model could only explain $24 \%$ of the variables, with poor fitting degree. Based on the geographical weighted 


\section{2}
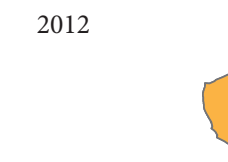

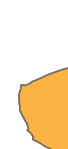

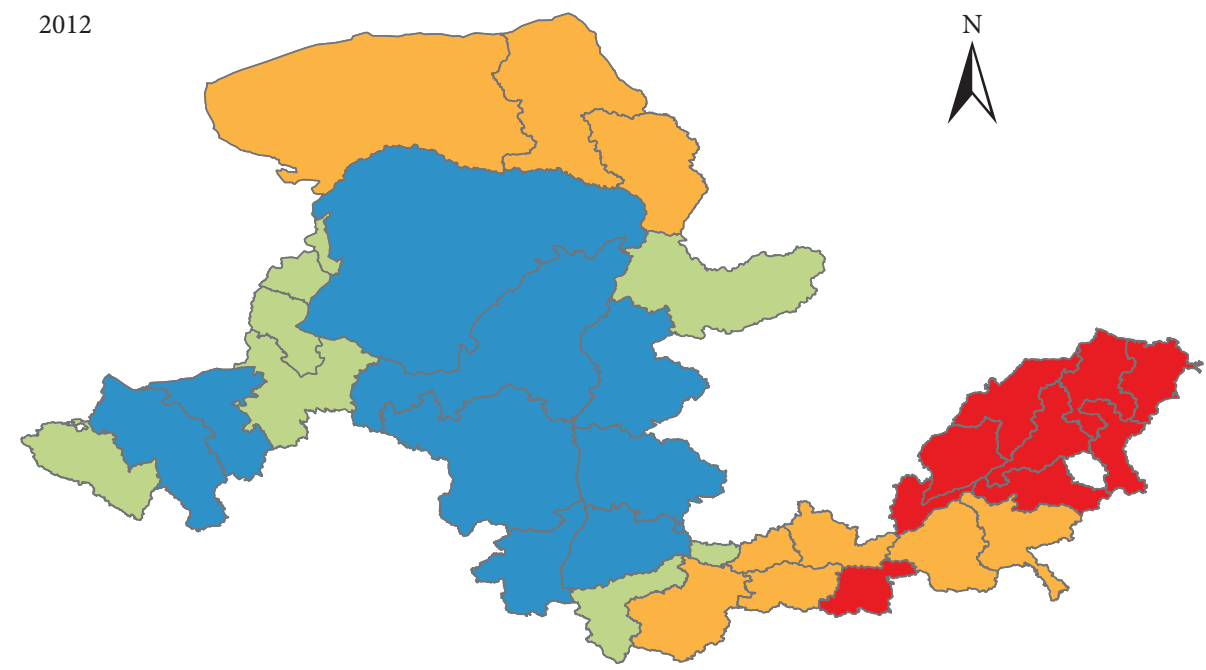

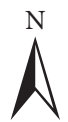

$\mathrm{Gi}^{*}$

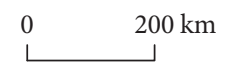

Cold spot area

Secondary cold spot area

Secondary hot spot area

Hot spot area

(a)

2015

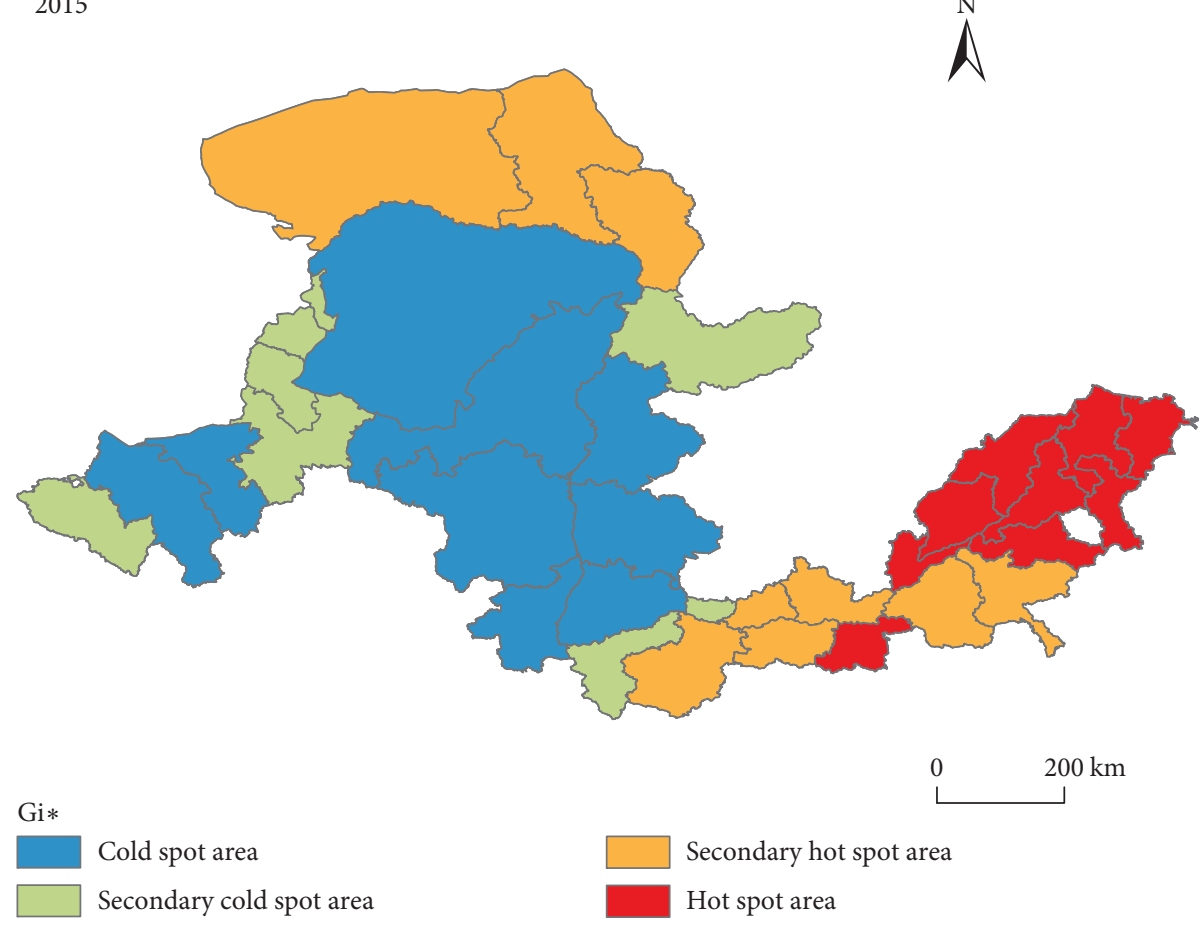

(b)

Figure 3: Continued. 


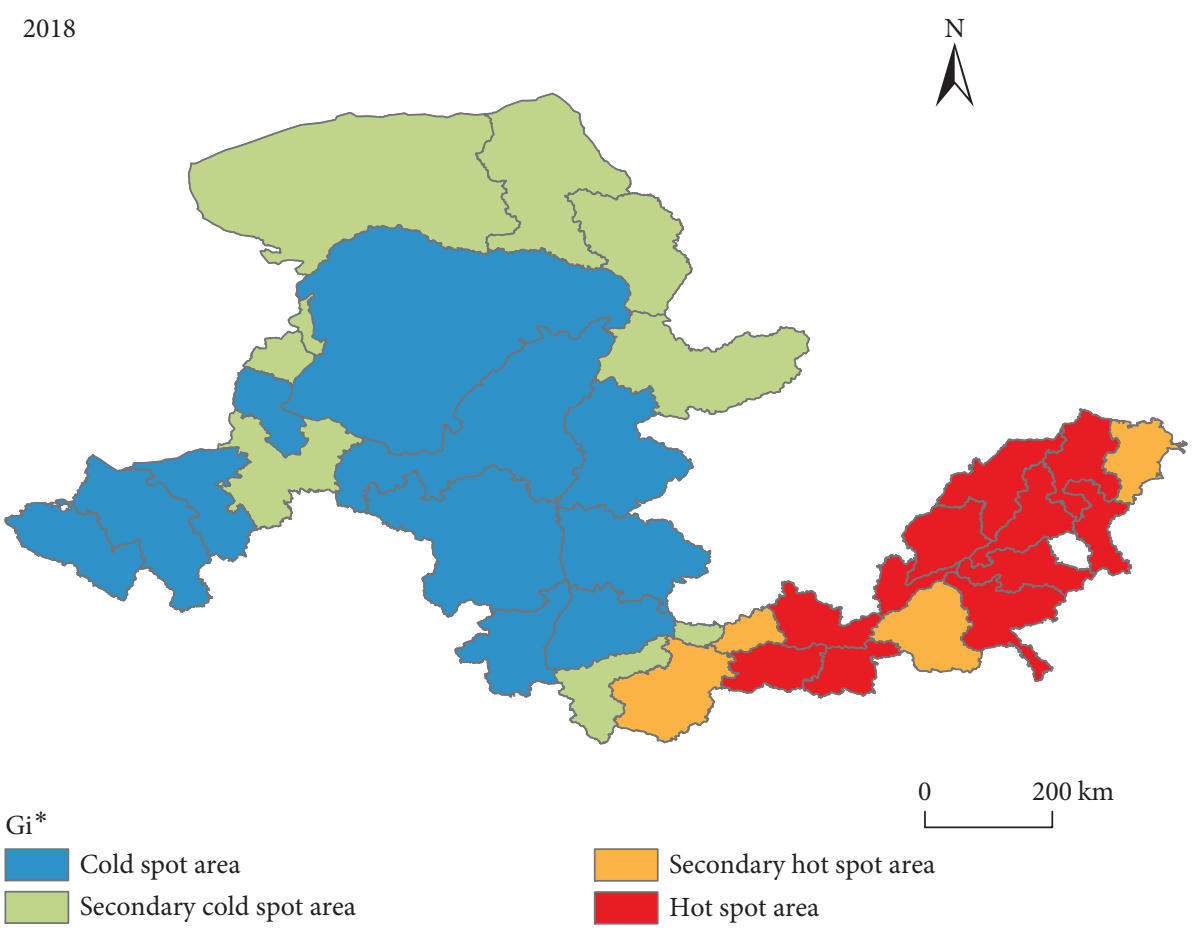

(c)

FIGURE 3: Spatial distribution of cold and hot spots of IGD in YRB in 2012, 2015, and 2018.

regression (GWR) analysis, the core type ADAPTIVE is selected, the bandwidth is AICc, and the result is $R^{2}=0.60$, $\mathrm{AICc}=-42.51$. The $R^{2}$ of the GWR model is much larger than that of the OLS model, and the difference of AICc is greater than 3. Relevant studies [43] show that if the difference of AICc is greater than 3, the GWR model is better. Hence, GWR model is selected for analysis in this paper.

Table 6 shows the regression coefficients of the calculation results. It can be seen from the results that the influence of each variable on IGD in each city is quite different. From the positive and negative aspects of the regression coefficients, industrial upgrading index, urbanization rate, total import and export to GDP, and science and technology expenditures show significant positive effects. The reduction rate of energy consumption varies from city to city. From the mean value of the regression coefficient, the influences of the five variables on IGD in YRB are ratio of total imports and exports to GDP > industrial upgrading index > urbanization rate $>$ science and technology expenditures $>$ reduction rate of energy consumption.

Figure 4 shows that the industrial upgrading index has a positive impact on IGD. To be specific, the regression coefficient of the industrial upgrading index of all cities in YRB is positive, which is distributed within the range of $0.0264-0.1742$. It indicates that the higher the industrial upgrading index, the higher the IGD. This is because the tertiary industry, represented by high-tech industry, is the gathering place of technical factors and talent factors. Its products are mainly products and services with high added value, which can promote IGD. At present, the secondary industry is still dominated by the traditional manufacturing industry, and the production factors are mainly raw materials and land. It is a pollution-intensive industry, which has an impeding effect on IGD. Therefore, theoretically speaking, the tertiary industry accounts for a larger proportion, while the secondary industry accounts for a smaller proportion, so the level of IGD in this region will be higher. In space, it presents the distribution characteristic of decreasing from the central region to the east and the west. The cities with high regression coefficient include Yuncheng, Sanmenxia, Luoyang, Jiyuan, Jiaozuo, Xinxiang, Kaifeng, and Zhengzhou. IGD of these cities is most affected by the industrial upgrading index. Yuncheng, Sanmenxia, and Jiaozuo are resource-based industrial cities with a large proportion of the secondary industry. In recent years, with the continuous upgrading of the industrial structure, the traditional manufacturing industry has gradually shifted to the service manufacturing industry. Both the proportion of tertiary industry and the level of IGD increased. Zhengzhou and Luoyang are big cities in economy, population, and 
TABLE 3: Influencing factors of IGD.

\begin{tabular}{lcc}
\hline Influence factor & Variable & Definition \\
\hline $\begin{array}{l}\text { Industrial structure } \\
\text { Urban development } \\
\text { potential }\end{array}$ & Industrial upgrading index & Added value of tertiary industry/secondary industry \\
Energy efficiency & Urbanization rate & Urban population/total population \\
$\begin{array}{l}\text { Degree of openness } \\
\text { Government support }\end{array}$ & $\begin{array}{c}\text { Total imports and exports to GDP ratio } \\
\text { Science and technology expenditures }\end{array}$ & $\begin{array}{c}\text { 1. Energy consumption per unit of GDP this year/energy } \\
\text { consumption per unit of GDP last year }\end{array}$ \\
\hline
\end{tabular}

TABLE 4: Collinearity test of influencing factors.

\begin{tabular}{lccc}
\hline Variable & Variance inflation factor (VIF) & Tolerance (T) & Conditional index (CI) \\
\hline Industrial upgrading index & 1.054 & 0.949 & 2.931 \\
Urbanization rate & 1.109 & 0.901 & 3.45 \\
Reduction rate of energy consumption per unit of GDP & 1.143 & 0.875 & 4.485 \\
Total imports and exports to GDP ratio & 1.046 & 0.956 & 7.024 \\
Science and technology expenditures & 1.083 & 0.923 & 14.555 \\
\hline
\end{tabular}

TABLE 5: Comparison of OLS regression and GWR regression results.

\begin{tabular}{lcc}
\hline & OLS & GWR \\
\hline$R^{2}$ & 0.24 & 0.60 \\
AICc & -35.52 & -42.51 \\
\hline
\end{tabular}

transportation with rich regional resources. The growth of industrial upgrading index means that the proportion of tertiary industry is rising, and the level of industrial greening is improving. There are 12 cities with regression coefficient between 0.0246 and 0.0480 , including Wuhai, Zhongwei, and Baiyin, with the smallest regression coefficient and the lowest influence degree. This is because Wuhai and Zhongwei are located in the west. They are still dominated by the secondary industry, and their economic strength and infrastructure are relatively weak. They can only undertake the traditional manufacturing industry eliminated by the east. It is difficult to develop the high-tech industry by relying on their own strength. Besides, the tertiary industry development is slow, and the industrial upgrading index of these regions has little impact on IGD.

In Figure 5, the regression coefficient of urbanization rate is positive, ranging from 0.0254 to 0.1079 , indicating that urbanization rate has a positive impact on IGD. The improvement of urbanization rate can drive IGD and is an important thrust for IGD in YRB. This is because the improvement of urbanization level is accompanied by the population gathering, the improvement of urban functions, and the optimization of spatial layout. These factors have created good conditions for IGD. The urbanization rate has a driving impact on IGD, while the influence degree of each city in YRB is different. The spatial distribution is low in the middle and high in both sides. 9 cities, including Lanzhou, Yinchuan, Ordos, Zhongwei, and Baiyin, are located in high-value districts. And IGD of these cities is most affected by the urbanization rate. The urbanization rate of Zhongwei, Wuzhong, and Baiyin is low, which is only
$30.45 \%, 50.18 \%$, and $50.62 \%$ in 2018 , far lower than other cities. The improvement potential is large, and IGD is strongly influenced by urbanization rate. The other highvalue areas are mainly concentrated in western cities such as Lanzhou and Yinchuan. There are two reasons: on the one hand, these cities are located to the west of the "Hu Line." China has implemented the western development policy, which promotes the population agglomeration of western cities. On the other hand, the urbanization rate of Lanzhou and Yinchuan reached $81.03 \%$ and $77.58 \%$ in 2018. It has reached the later stage of urbanization, and urban development is in urgent need of support from talents. In 2017, many cities began the "war for talents." In order to retain talents, Lanzhou lowered the threshold of becoming urban residents, which increased the urban population and provided talent support for IGD. The lowvalue areas of regression coefficient are mainly concentrated in 8 cities, including Xinzhou, Luliang, Linfen, and Jiaozuo. This may be because most of these cities are close to the provincial capitals, which have a greater radiation effect on them. Compared with provincial capitals, the attraction to talents, especially high-end talents, is lower, and the accumulation of human capital is slower. There is no sufficient support of talents, transformation and upgrading of industries are slow, and the promotion of IGD is less.

Figure 6 shows that the change rate of energy consumption has positive and negative impact on IGD. In other words, the faster the reduction rate of energy consumption in some regions, the higher the IGD level. This can be caused by two reasons: first, more than $70 \%$ of China's current 
TABLE 6: Results of the GWR model.

\begin{tabular}{|c|c|c|c|c|c|}
\hline & Minimum & Lower quartile & Mean & Upper quartile & Maximum \\
\hline Industrial upgrading index & 0.0264 & 0.0445 & 0.0858 & 0.1158 & 0.1743 \\
\hline Urbanization rate & 0.0254 & 0.0508 & 0.0708 & 0.0964 & 0.1079 \\
\hline Reduction rate of energy consumption per unit of GDP & -0.1506 & -0.1112 & -0.0231 & 0.0600 & 0.0809 \\
\hline Ratio of total imports and exports to GDP & 0.0282 & 0.1467 & 0.1997 & 0.2551 & 0.3002 \\
\hline Science and technology expenditures & 0.0148 & 0.0274 & 0.0514 & 0.0652 & 0.0847 \\
\hline
\end{tabular}

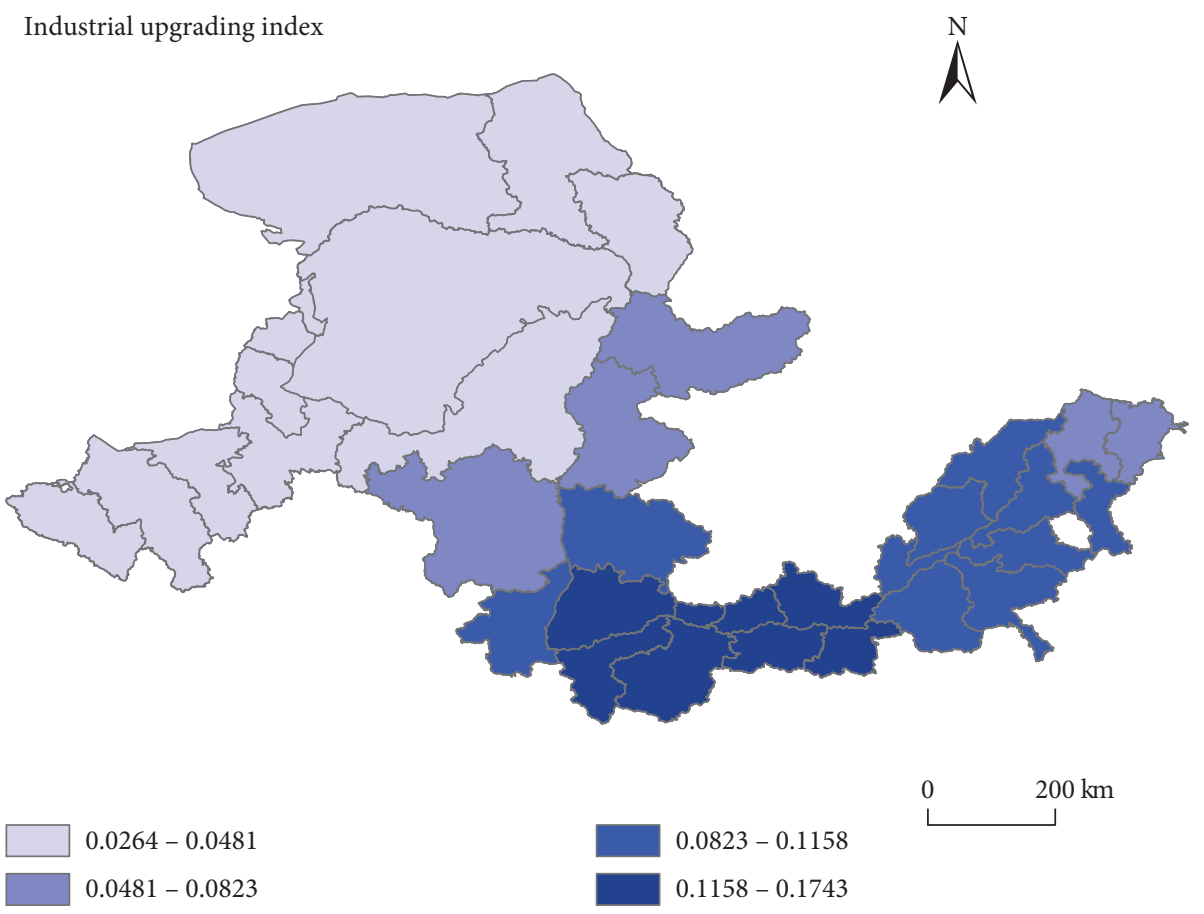

FIGURE 4: Spatial distribution of regression coefficient of the industrial upgrading index on IGD.

energy use is nonclean. Energy consumption is accompanied by the generation of pollutants and wastes, which has a negative impact on environmental development. Improving the utilization rate of energy, using clean energy, advocating "green economy," and opposing "black economy" can effectively protect the ecological environment, which is conducive to IGD. Second, the total amount of fossil energy is limited. Coal is a nonrenewable and highly polluting energy source. For high-polluting enterprises, the effective way to reduce the use of polluting energy is to increase the utilization rate of resources and create more value with less resource. In this way, the reduction of energy consumption promotes IGD. From the perspective of spatial distribution, reduction rate of energy consumption in each city has different impacts on IGD, showing a spatial distribution decreasing from west to east. The most influential cities are Shizuishan, Yinchuan, Hohhot, etc., with the regression coefficient being between -0.1505 and -0.1082 . There are two main reasons: on the one hand, the rate of decline in energy consumption is relatively high, which makes the level of IGD improve rapidly. According to the original data, the energy consumption of Shizuishan and Yinchuan decreased by $9.5 \%$ and $12 \%$, respectively, much faster than the national average. On the other hand, clean energy consumption reduces energy consumption. Statistics show that clean energy consumption in these cities accounted for nearly $40 \%$ in 2019, well above the national average. The use of clean energy is bound to reduce the use of polluting energy, which is conducive to driving down the rate of energy consumption. Based on the above two reasons, the reduction rate of energy consumption in these cities has a great negative impact on IGD. The reduction rate of energy consumption in Henan and Shandong provinces has a small and basically positive influence on IGD. This may be because the development of the two provinces is in a dominant position in YRB, and the development degree of dependence on traditional energy is small. Reduction rate of energy consumption is much lower than that of other regions, and the rate of decline is not as fast as that of other regions. Therefore, the reduction rate of energy consumption in these two provinces promotes IGD.

In Figure 7, openness has a positive impact on IGD. The regression coefficient of the total imports and exports to GDP is positive, between 0.0282 and 0.3001 , indicating that the more open the economy, the more conducive to IGD. This shows that all regions in YRB have successfully crossed the stages of "pollution refuge effect" and "pollutant paradise hypothesis." With the deepening of the 


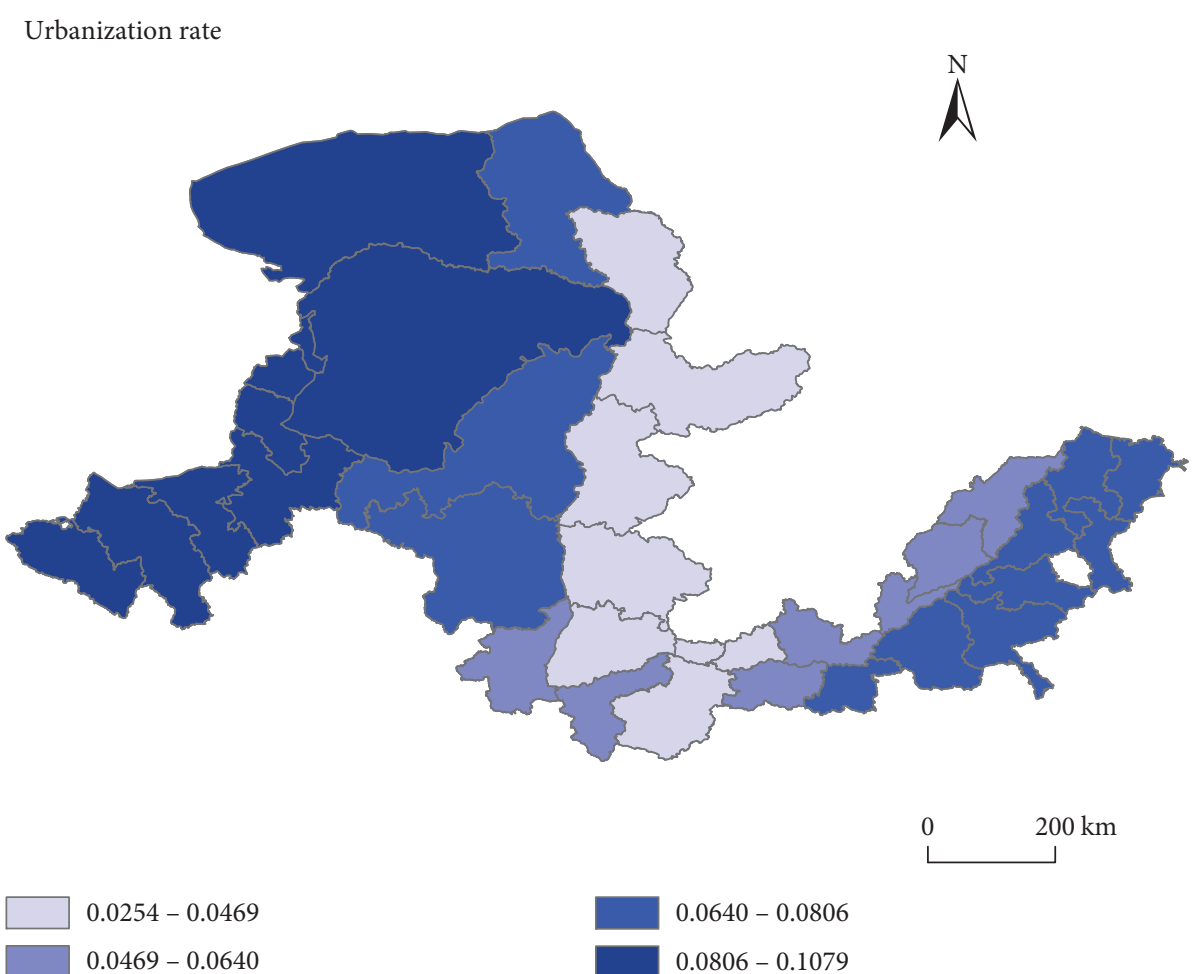

FIGURE 5: Spatial distribution of the coefficient of urbanization rate to IGD.

concept of sustainable development, the requirement of the import and export goods is increasing. From the perspective of spatial layout, the regression coefficient shows the spatial feature of decreasing from the center to both sides. The coefficient of Zhengzhou, Jiaozuo, Luoyang, and Linfen is larger, and IGD of these cities is greatly influenced by the open economy; conversely, the influence of Bayannaoer and Baotou is smaller. The reason mainly has the following two aspects: on the one hand, Zhengzhou and other cities have relatively developed transportation facilities and are closely connected with the world. Zhengzhou is an important transportation hub in China, and Zhengzhou Aviation Port Area is the only national aviation port economic comprehensive experimental area in China, with relatively perfect infrastructure and conditions for the transformation to an export-oriented city. However, Bayannaoer and Baotou are located in the western region of China, where all kinds of transportation modes are relatively backward and have few economic connections with the world. Although the ratio of total imports and exports to GDP promotes local IGD, it is relatively small. On the other hand, the added value of import and export goods is different. Zhengzhou is a new major city of China, and the added value of import and export products is higher compared to Bayannaoer.

Figure 8 shows that science and technology expenditures have a significant positive influence on IGD, and the degree of impact varies from city to city. Specifically, the regression coefficient of science and technology expenditures is between 0.0148 and 0.0847 . The high-value areas include Linfen, Luliang, and Hohhot, and the regression coefficient is between 0.0651 and 0.0847 . It may be because the level of science and technology in these cities is low, and the marginal effect of investment in science and technology is significant. The 2019 government work report shows that, in 2018, Hohhot strategic emerging industries output value accounts for $30 \%$ of industrial output value above designated scale, and the contribution rate of science and technology to economic growth increased to $56 \%$. It proves that the input of science and technology in Hohhot is in direct proportion to the output, and increasing the expenditure of science and technology is conducive to IGD. The low-value areas of regression coefficient are Bayannaoer, Baiyin, Ordos, Lanzhou, Shizuishan, Wuhai, Wuzhong, Zhongwei, Yinchuan, and Baotou, whose scientific and technological expenditure had little influence on IGD. There are two reasons: on the one hand, there is time lag of science and technology expenditures. Science and technology expenditures are mainly used for scientific research and cultivating talents. These cities are not that attractive to high-end talents. The implementation of western development policy has attracted some talent; however, it still needs time to translate them into innovative results. On the other hand, the innovation efficiency of these cities needs to be improved. These cities cannot ignore the insufficient investment in science and education in green development and low efficiency in research and development. Due to low efficiency, the innovation results are not timely and accurately applied to the green industry, which has little impact on IGD. 
Reduction rate of energy consumption per unit of GDP

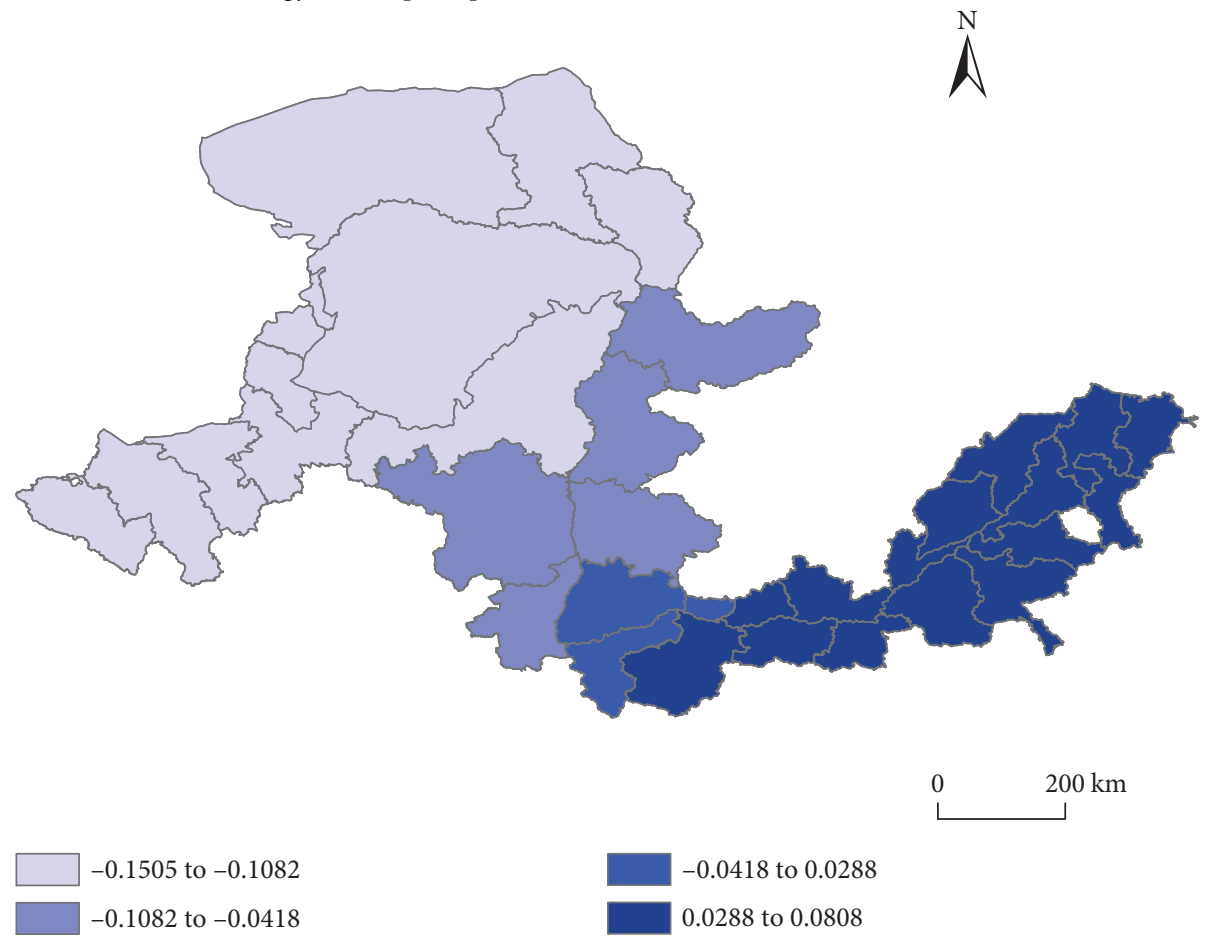

FIGURE 6: Spatial distribution of the regression coefficient of the reduction rate of energy consumption on IGD.

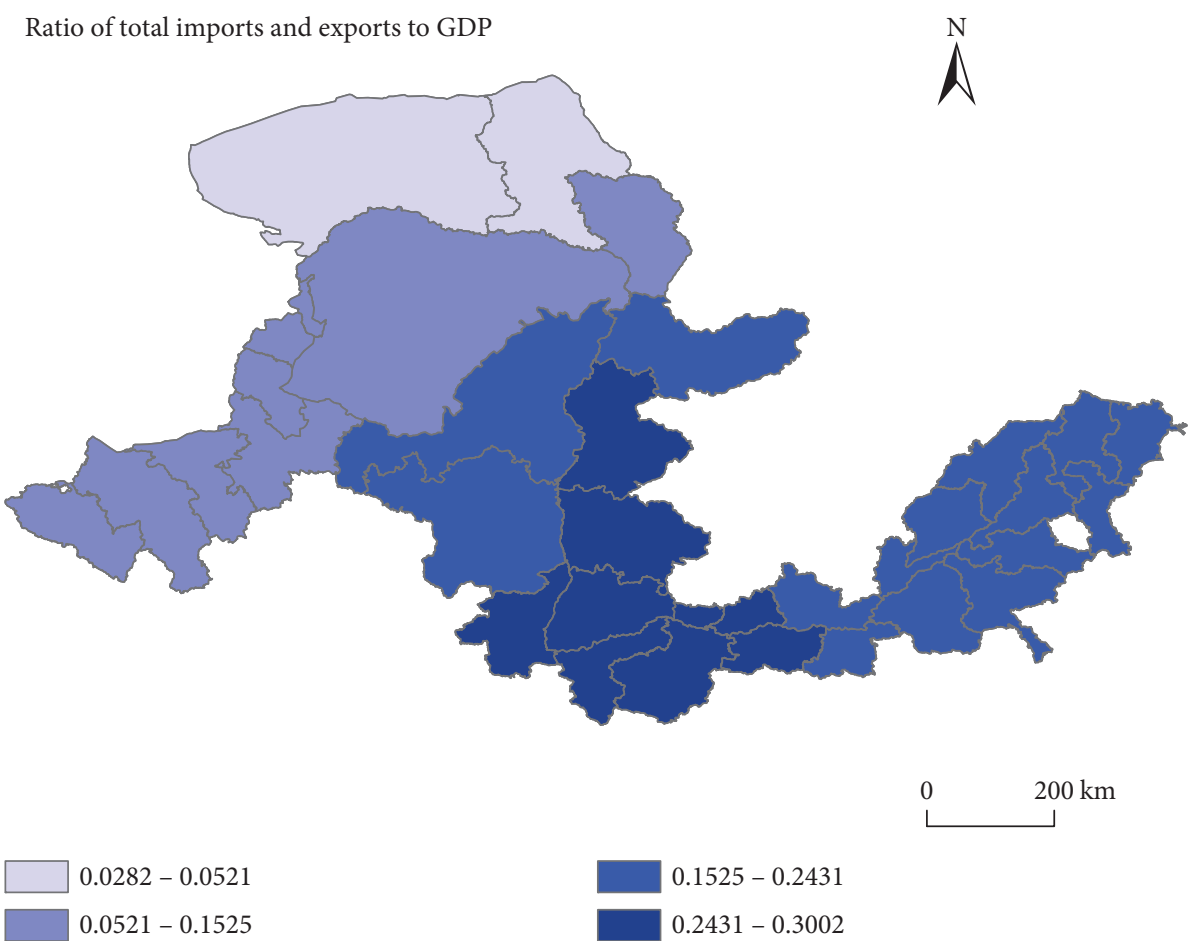

FIGURE 7: Spatial distribution of regression coefficient of total imports and exports to GDP on IGD. 
Science and technology expenditures

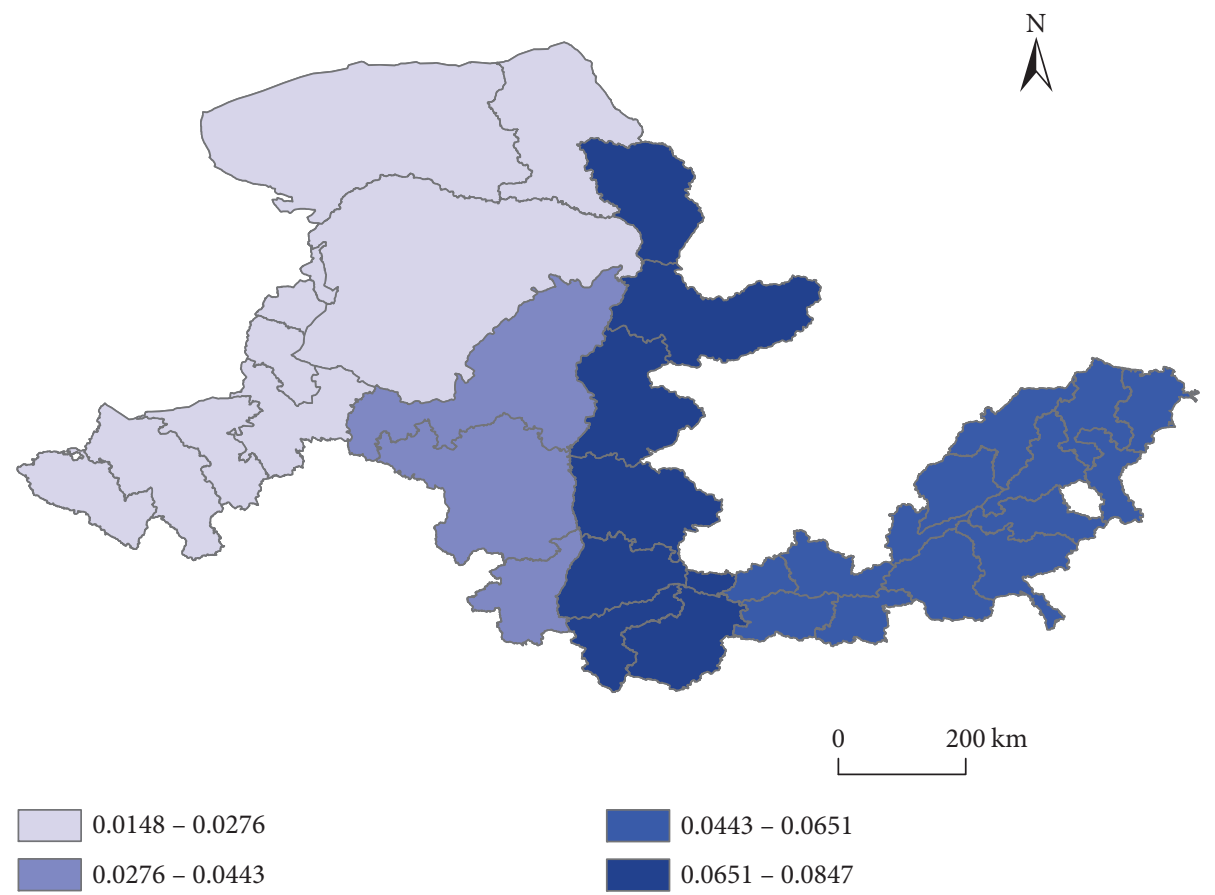

FIGURE 8: Spatial distribution of the regression coefficient of science and technology expenditures on IGD.

\section{Conclusion and Recommendation}

6.1. Conclusion. This paper constructs an evaluation index system for IGD in YRB through three dimensions: economic green growth, resource and environmental carrying capacity, and government support. The spatial evolution characteristics of 35 cities in YRB in 2012, 2015, and 2018 are investigated by using ESDA. And we use the GWR model to analyze the influencing factors of IGD in YRB. The main conclusions and recommendations are as follows.

First, IGD in YRB is generally on the rise. From the perspective of time, IGD in all cities in YRB in 2018 has increased compared with that in 2012. From the perspective of spatial dimension, IGD is still high in the east and low in the west, and the gap is getting larger and larger. Zhengzhou and Jinan are high-value areas, while Zhongwei and Wuzhong are low-value areas for IGD.

Second, there is a spatial positive correlation among IGD in YRB. The Global Moran's I in 2012, 2015, and 2018 are all positive with a small change, indicating that the spatial distribution of IGD in YRB is relatively stable. There is no substantial change in the local analysis pattern of cold and hot spots, which maintains the distribution characteristics of "high in the east and low in the west." Jinan, Dezhou, and Zhengzhou are always hot spots, driving IGD of surrounding, while there are no hot spots in the western region.

Thirdly, there are obvious regional differences in the factors influencing IGD in YRB. In general, the degree of influence of each influencing factor on IGD is as follows: openness $>$ industrial upgrading index $>$ urbanization rate$>$ science and technology expenditures $>$ reduction rate of energy consumption. Among them, industrial upgrading index, urbanization rate, openness, and science and technology expenditures show significant positive effects. The reduction rate of energy consumption varies with cities.

6.2. Recommendation. First, the government should play its full role and strengthen environmental control. The government has a very important influence on IGD. It is found from the previous research that the government plays a vital role in IGD in the YRB. In terms of policy formulation, the government needs to set targets to constrain enterprises. Although some achievements have been made, the target system is not perfect enough, and the discharge of waste water and waste gas from industrial enterprises still needs to be solved. Therefore, the government should formulate corresponding policies according to local conditions to supervise enterprises and limit their discharge of waste water, gas, and waste. From a financial point of view, the government will increase spending on energy conservation and environmental protection to help enterprises achieve green transformation. Application of new energy and new technology is accompanied by the rising cost of enterprises. It is far from enough to drive the application of new energy only by the social responsibility of enterprises. At this time, the government needs to subsidize new energy and new technologies and encourage their application in production to realize green production and clean production.

Second, use urban agglomeration to increase the efficiency of rural areas. Rural areas in YRB are relatively weak links in IGD. It is difficult to improve IGD only by relying on the rural strength. Therefore, on the one hand, it is necessary to encourage the cultivation of industrial chain links between urban and rural enterprises. At the same time, the 
government can guide urban residents to increase localized consumption of agricultural products, support the joint development of public marketing platforms for agricultural products or rural industries between regions and between urban and rural areas, and enhance the radiation driving effect of urban industrial transformation and upgrading and IGD in rural. On the other hand, the development of tourism in YRB should make use of the metropolitan area. Relying on the magnificent and beautiful natural landscape and timehonored historical culture of YRB, combined with the characteristics of each city, the metropolis circle is utilized to develop tourism in YRB, drive the development of related industries, as catering, trade and logistics, and tourism commodity manufacturing, and enhance IGD.

Third, realize industrial transformation and upgrading and support the high-tech industries. Traditional industries are the main body of pollutant discharge, so transforming and upgrading them and eliminating backward industries are conducive to IGD. The cities in YRB have a large proportion of traditional industries. Due to relatively backward economy, they are the receiving places for industrial transfer of foreign-funded enterprises and the Yangtze River Delta region. When undertaking industrial transfer, the standard should be improved to avoid becoming a "pollution refuge." At the same time, existing industries should be transformed and upgraded from the root and increase the added value of products and reduce energy consumption. High-tech products have high added value. Generally speaking, cities with high-tech industries have a high level of green development. These require cities, on the one hand, to make full use of technical factors, personnel factors, and capital factors to develop local high-tech industries and, on the other hand, to improve the infrastructure of the city and enhance the soft power of the city, to encourage high-tech industries to cluster together.

Fourth, building a mechanism for regional coordination and cooperation enhances interconnected regional industrial development. Region industrial development is one of the effective ways to realize the coordinated development of regions. Different cities in YRB have different levels of IGD. Generally speaking, the level of IGD in the east of YRB is higher than that in the west. A cooperation mechanism should be established within the region. On the one hand, establish sharing mechanisms. The mechanism of regional coordination and cooperation should be shared first, emphasizing information sharing, resource sharing, and infrastructure sharing, which can effectively reduce the disordered industrial competition in cities along the route and improve the systematization and coordination of industrial development in YRB. On the other hand, resources in the upstream and downstream should be integrated to promote the division of labor and cooperation. There is a big gap between the upstream and downstream of YRB. Cities in YRB should give play to their comparative advantages, build platforms for undertaking industrial transfer in the upper, middle, and lower reaches, and cultivate characteristic industrial parks to promote the integrated development of upstream and downstream industries.
Fifth, cultivate scientific research and innovation teams and facilitate the integrated industrial development, universities, and research institutes. Scientific and technological innovation is the source of vitality for IGD, and cultivating $\mathrm{R} \& \mathrm{D}$ teams is conducive to IGD. At present, the industry in YRB lacks innovation vitality. In agriculture, the use of chemical fertilizers and pesticides is relatively much, and the cultivation of new varieties to promote the development of agricultural mechanization requires the efforts of scientific research teams. In industry, the coverage rate of clean production and green production is low, resulting in high pollution level of enterprises and incomplete industrial chain structure. This requires the extension of industrial chain and the search for new growth points of the industry, as well as scientific research support. In the tertiary industry, it is necessary to keep innovative vitality to promote enterprises in an invincible position. However, there is a disconnect between education, research, and business. Universities, research centers, and enterprises lack cooperation. This requires cities in YRB to strengthen the integrated development of industry, education, and research. For colleges and universities to train corresponding talents for enterprises, the research center develops much-needed technology for enterprises, and enterprises provide employment opportunities for colleges and universities, provide financial support for scientific research centers, and promote long-term win-win cooperation.

\section{Data Availability}

The data used to support the findings of this study are available from the corresponding author upon request.

\section{Conflicts of Interest}

The authors declare that they have no conflicts of interest.

\section{Acknowledgments}

This work was supported by grants from the National Social Science Foundation of China (20CJY064) and Think Tank Research Project of Higher Education Institutions of Henan Province in 2021 (2021-ZKYJ-06).

\section{References}

[1] Y. Chen, W. Tian, Q. Zhou, and T. Shi, "Analysis of the temporal and spatial patterns and driving forces of ecological carrying capacity in urban high-quality development-an empirical analysis based on samples of 286 cities in China," Journal of Cleaner Production, vol. 293, 2021.

[2] S. Kumari and Y. B. Patil, "Enablers of sustainable industrial ecosystem: framework and future research directions," Management of Environmental Quality: An International Journal, vol. 30, no. 1, pp. 61-86, 2019.

[3] D. W. Pearce and E. Barbier, Blueprint for a Green Economy, Routledge, London, UK, 1989.

[4] L. L. Wang and Y. G. Zhang, “"Green development” connotation exploration," Socialism Studies, no. 5, pp. 143-146, 2012. 
[5] S. Z. Gu, M. E. Xie, X. H. Zhang, and W. Q. Huang, "Study on the new concept and measures of green development," Environmental Protection, vol. 44, no. 12, pp. 13-15, 2016.

[6] X. Tian, H. Gao, and Y. L. Xiong, "Implement green development mode and promote green development: Yangtze River economic belt as a model," Environmental Protection, vol. 47, no. 18, pp. 26-31, 2019.

[7] P. Ren and J. W. Liu, "Theoretical connotation, evaluation criteria and path to realization of high quality green development," Inner Mongolia Social Sciences, vol. 40, no. 6, pp. 123-131+213, 2019.

[8] B. Z. Zhu, M. F. Zhang, Y. H. Zhou et al., "Exploring the effect of industrial structure adjustment on interprovincial green development efficiency in China: a novel integrated approach," Energy Policy, vol. 134, p. 12, 2019.

[9] Q. Yang, X. Wan, and H. Ma, “Assessing green development efficiency of municipalities and provinces in China integrating models of super-efficiency DEA and malmquist index," Sustainability, vol. 7, no. 4, pp. 4492-4510, 2015.

[10] Y. Qu, Y. Yu, A. Appolloni, M. R. Li, and Y. Liu, "Measuring green growth efficiency for Chinese manufacturing industries," Sustainability, vol. 9, no. 4, p. 18, 2017.

[11] Q. Li, "Regional technological innovation and green economic efficiency based on DEA model and fuzzy evaluation," Journal of Intelligent \& Fuzzy Systems, vol. 37, no. 5, pp. 6415-6425, 2019.

[12] W. H. Yuan, J. C. Li, L. Meng, X. N. Qin, and X. X. Qi, "Measuring the area green efficiency and the influencing factors in urban agglomeration," Journal of Cleaner Production, vol. 241, p. 12, 2019.

[13] OECD, Towards Green Growth, OECD Publishing, Paris, France, 2011.

[14] L. Li and Z. H. Chu, "Evaluation and dynamic comparison of my country's regional industrial green development index," Economic Research, no. 1, pp. 68-75, 2015.

[15] S. Z. Huang, L. Yang, X. Y. Yang, and X. G. Li, "Huangshan city, Anhui province green development trend of time and space," Resources and Environment in the Yangtze Basin, vol. 28, no. 8, pp. 1872-1885, 2019.

[16] G.-j. Zhang, M.-y. Deng, Y.-y. Yao, and X.-y. Li, "Comprehensive level of the green development of industry in Guangdong province and spatial econometric analysis of the influencing factors," Journal of Natural Resources, vol. 34, no. 8, pp. 1593-1605, 2019.

[17] H. X. Zheng, Y. Wang, and B. R. Huang, "A research review on green development indicator system," Journal of Industrial Technological Economics, vol. 33, no. 2, pp. 142-152, 2013.

[18] X. X. Feng, C. H. Zhu, and H. F. Yue, "Evaluation of industrial green growth in Sichuan province: based on 21 cities' panel data," Finance \& Economics, no. 9, pp. 72-83, 2017.

[19] J. M. Reilly, "Green growth and the efficient use of natural resources," Energy Economics, vol. 34, pp. S85-S93, 2012.

[20] A. Pan, Q. Wang, and Q. Yang, "Assessment on the coordinated development oriented to Green City in China," Ecological Indicators, vol. 116, p. 9, 2020.

[21] J. Han, "Research on the measurement of Chinese industrial greening level and its influencing factors," Chinese Journal of Population Resources and Environment, 2012.

[22] G. Cainelli, M. Mazzanti, and R. Zoboli, "Environmental innovations, complementarity and local/global cooperation: evidence from North-East Italian industry," International Journal of Technology, Policy and Management, vol. 11, no. 34, pp. 328-368, 2011.
[23] C. F. Chen, J. Han, and P. L. Fan, "Measuring the level of industrial green development and exploring its influencing factors: empirical evidence from China's 30 provinces," Sustainability, vol. 8, no. 2, p. 20, 2016.

[24] M. Artmann, M. Kohler, G. Meinel, J. Gan, and I.-C. Ioja, "How smart growth and green infrastructure can mutually support each other-a conceptual framework for compact and green cities," Ecological Indicators, vol. 96, pp. 10-22, 2019.

[25] X. B. He, "Influences of urbanization on China's economic growth quality:an empirical analysis based on provincial panel data," Urban Problems, no. 1, pp. 4-13, 2019.

[26] F. Y. Guo, X. Lv, W. Yu, J. M. Ren, and N. C. Chu, "Performance evaluation and driving mechanism of green development in Shandong province based on panel data of 17 cities," Scientia Geographica Sinica, vol. 40, no. 2, pp. 200-210, 2020.

[27] B. Wang, W. S. Tang, Y. R. Wu, and N. Zhang, "Does urbanization increase China's green development efficiency?" Economic Review, no. 4, pp. 38-49+107, 2014.

[28] L. Zhou, L. Lei, and C. H. Zhou, "Spatio-temporal evolution and influencing factors of urban green development efficiency in China," Acta Geographica Sinica, vol. 74, no. 10, pp. 2027-2044, 2019.

[29] D. Alexi and I. Romero, "Environmental conflict analysis using an integrated gray clustering and entropy-weight method: a case of a mining project in Peru," Environmental Modeling \& Software, vol. 77, pp. 108-121, 2016.

[30] J. Yu, H. Shen, J. Gou, and X. Zhang, "The green environment measurement by entropy method: a study based on Minnan coastal area in China," Journal of Coastal Research, vol. 103, no. sp1, pp. 442-446, 2020.

[31] W. J. Guo and F. H. Huang, "The impact of high-tech industry agglomeration on economic growth quality: an empirical study based on economic growth quality: an empirical study based on China's provincial panel data," Inquiry into Economic Issues, no. 3, pp. 150-164, 2021.

[32] Y. Chen, M. Zhu, J. Lu, Q. Zhou, and W. Ma, "Evaluation of ecological city and analysis of obstacle factors under the background of high-quality development: taking cities in the Yellow River Basin as examples," Ecological Indicators, vol. 118, 2020.

[33] H. R. Ren, Y. J. Shang, and S. Zhang, "Measuring the spatiotemporal variations of vegetation net primary productivity in inner mongolia using spatial autocorrelation," Ecological Indicators, vol. 112, p. 7, 2020.

[34] X. Y. Hu, Z. L. Zhang, X. P. Chen, and Y. J. Wang, "Geographic detection of spatial-temporal difference and its influencing factors on county economic development: a case study of Gansu province," Geographical Research, vol. 38, no. 4, pp. 772-783, 2019.

[35] A. Fotheringham, Geographically Weighted Regression, Wiley, New York, NY, USA, 2002.

[36] J. Chen, C. Zhou, S. Wang, and J. Hu, "Identifying the socioeconomic determinants of population exposure to particulate matter (PM2.5) in China using geographically weighted regression modeling," Environmental Pollution, vol. 241, pp. 494-503, 2018.

[37] H. G. Gao and L. Zhao, "Green development level measurement and spatial difference analysis of Yangtze River economic belt," Science \& Technology Progress and Policy, vol. 36, no. 12, pp. 46-53, 2019.

[38] S. J. Guo, W. B. Mi, and Y. Zhao, "Spatial variation and relevant influence factors of green development levels among 
the counties in Ningxia," Economic Geography, vol. 35, no. 3, pp. $45-51+48,2015$.

[39] K. Liu, Y. Qiao, T. Shi, and Q. Zhou, "Study on coupling coordination and spatiotemporal heterogeneity between economic development and ecological environment of cities along the Yellow River Basin," Environmental Science and Pollution Research, vol. 28, no. 6, pp. 6898-6912, 2021.

[40] Y. Chen, M. K. Zhu, Q. Zhou, and Y. R. Qiao, "Research on spatiotemporal differentiation and influence mechanism of urban resilience in China based on MGWR model," International Journal of Environmental Research and Public Health, vol. 18, no. 3, 2021.

[41] H. Zhang, C. Luo, J. H. Luo, and H. T. Wang, "The level of green development and its spatial relationship in hubei province," Economic Geography, vol. 36, no. 9, pp. 158-165, 2016.

[42] S. Z. Tian and Y. J. Ding, "Greenization measurement of urban agglomeration in Yangtze River Delta and its influence factors: an empirical study based on the entropy-tobit model of 26 cities' panel data," Economic Geography, vol. 39, no. 9, pp. 94-103, 2019.

[43] H. Akaike, "A new look at the statistical model identification," IEEE Transactions on Automatic Control, vol. 19, no. 6, 1974. 